\title{
To what extent is Australia's population ageing? The application of traditional and alternative ageing measures
}

Tom Wilson* The University of Melbourne

Jeromey Temple The University of Melbourne

* Corresponding author. Email: wilson.t1@unimelb.edu.au. Address: Melbourne School of Population and Global Health, The University of Melbourne, 207 Bouverie St, Melbourne, Vic 3010, Australia.

Paper received 28 February 2020; accepted 11 May 2020; published 25 May 2020.

\section{Abstract}

\section{Background}

Most studies of population ageing apply traditional ageing measures, such as the number or percentage of the population aged 65 and above. In the context of gradually improving health and mortality at age 65 , the use of a fixed age cut-off to define 'older age' needs to be revisited.

\section{Aim}

The aim of this paper is to re-assess the extent of population ageing in Australia and the States and Territories over past decades and in the future as indicated by both traditional and alternative ageing measures.

\section{Data and methods}

Both numerical and structural ageing was measured using age cut-offs for the older population of (i) age 65, (ii) the age at which there is 15 years life expectancy remaining, and (iii) the age at which the mortality rate is above 0.01 . The data consisted of life tables, population estimates and population projections.

\section{Results}

Both traditional and alternative ageing measures indicate considerable past and future numerical ageing. Structural ageing has been strong since the 1970s in terms of the percentage aged 65+, but the alternative ageing measures paint quite a different picture of structural ageing both in the past and in the future.

\section{Conclusions}

The use of a traditional measure of population ageing in combination with a mortality-based measure, such as the population with remaining life expectancy of under 15 years, is helpful for demographic analyses of ageing.

\section{Key words}

Population ageing; characteristics approach; Australia; States and Territories. 


\section{Introduction}

In common with almost all countries of the world (UN 2019), Australia's population is undergoing population ageing. Traditional measures of population ageing include the numbers and proportions aged 65 and over, the Elderly Dependency Ratio (the ratio of the population aged 65+ to those aged 2064), the Ageing Index (the ratio of the population aged 65+ to those aged 0-19), and median age (Hobbs 2004; Rowland 2003). According to these traditional measures, Australia's population is clearly undergoing ageing - both numerical ageing in which the absolute number of older people is growing, and structural ageing in which the proportion of the population in the older ages is increasing. For example, over the 20 years to 2018 the population aged $65+$ increased from 2.3 million to 3.9 million, while the share of the total population in this age group rose from $12.2 \%$ to $15.7 \%$ (ABS 2019a).

Traditional ageing measures implicitly refer to the overall 'burden' of an older population, including the costs associated with services such as health care, aged pension payments, home care packages, and residential aged care. But Australians aged 65 today are generally in a much better position in terms of health and mortality relative to those of the same age many decades ago. For example, Australian men aged 65 in 2018 had a life expectancy of 20.3 remaining years compared to 12.1 years 50 years earlier (authors' life table calculations). The use of a chronological age cut-off for defining the older population which is invariant over time and space is not useful for many policy purposes.

Over the last decade or so several authors have proposed alternative measures of population ageing which reflect the shifting levels and age patterns of mortality, health, wellbeing, and economic activity (e.g. Chomik et al. 2016; Falkingham 2016; Sanderson and Scherbov 2007; Sanderson and Scherbov 2015; Skirbekk et al. 2012; Spijker 2015; Spijker and Maclnnes 2013). Sanderson and Scherbov (2013) argue that the threshold of old age is best defined by a selected population characteristic, such as a certain number of years of life expectancy remaining, a particular mortality rate, or pension eligibility ages (which are slowly rising in some countries). The characteristic of 15 years remaining life expectancy has proved popular and been used in several studies as the starting age of old age (e.g. Lutz et al. 2008; Sanderson and Scherbov 2008; UN 2019). This "characteristics approach" to the measurement of population ageing therefore permits the onset of old age to vary over time and space, or between different sub-groups of a national population.

A large number of studies on population ageing in Australia exist, most of which employ traditional ageing measures. Chomik et al. (2016) is one of the few exceptions. These authors use alternative dependency metrics for Australia based on health and economic data. The aim of this paper is to reassess the extent to which the populations of Australia and the States and Territories are ageing as indicated by both traditional and alternative ageing measures. Ageing is evaluated using actual data from 1921 to the present at the national scale, and from 1971 to the present at the State and Territory scale, and then out to 2066 using our own projections. In section 2 below we describe the data we use, including projected populations and life tables, and define the chosen traditional and alternative measures of population ageing that are applied. The results are presented and discussed in section 3 , followed by some concluding remarks about the alternative ageing measures and Australia's population ageing in the final section. In a rapidly ageing society, the demand for amenity, social support, and health and aged care facilities are of growing concern (Piggott et al. 2016), and the regional differences in migration flows have increasingly significant socioeconomic, political, and 
developmental implications (Jackson \& Felmingham 2002). As understanding the past trends of elderly migration can assist in predicting and planning for future growth, the aim of this paper is to understand how the impact of migration for older Australians has changed over the past forty years in comparison to the total population. To achieve this aim, this paper first establishes the national-level intensity, effectiveness, and impact of migration for each of the eight census periods from 1976-81 to 2011-16. The paper then maps the impact of these moves at the regional level to identify which regions are experiencing gains and losses. Finally, the paper speculates on possible explanations for the observed trends.

\section{Data and methods}

\subsection{Data}

The population estimates used in this study include national and State/Territory Estimated Resident Populations (ERPs) from the ABS from 1971-2019 (ABS 2019a) as well as national population estimates from 1921-1970 obtained from the Human Mortality Database (HMD 2019). National and State/Territory death counts by sex and single years of age were sourced from the ABS for the period 1971-2018 (ABS 2019b) while national deaths for 1921-1970 were obtained from the HMD (2019). National scale population estimates above age 85 for 1971-2018 were those estimated by Wilson and Temple (2020) using extinct cohort and survivor ratio methods, which tend to be more accurate than ERPs at the highest ages.

Life tables were created for each year from 1921 to 2018 for Australia and from 1971 to 2018 for each of the States and Territories. These were based on the formulae set out in Preston et al. (2001). Age-specific death rates were calculated for abridged life table age groups for the two territories and Tasmania due to the small numbers of deaths by age and sex in those jurisdictions. The grouped death rates were then interpolated to single years of age using cubic splines (above age 25) and linear splines at younger ages (where cubic splines work less well).

Population projections for Australia and the States and Territories were created using a cohortcomponent projection model. The projections started with 2016 ERPs and extended out to 2066, with projections in the short-run up to 2018 constrained to known demographic parameters. The projections were based on 'business as usual' assumptions after 2018, reflecting fertility and migration trends of recent years. Immigration and emigration flows were constrained to an annual net overseas migration assumption of 225,000 , while projected interstate in- and out-migration flows were constrained to the average annual net interstate migration values of the 2011-16 intercensal period. National fertility was set to a long-run Total Fertility Rate of 1.75, with State and Territory TFRs varying by fixed differentials based on recent trends. Mortality projections were derived from a long-run extrapolation of age-specific death rates using Ediev's (2008) method. State and Territory life expectancy at birth was assumed to move in parallel with national life expectancy into the future. Age-specific death rates corresponding to each life expectancy assumption were selected from the national mortality projections (Wilson 2018) for every jurisdiction except the Northern Territory. A separate mortality projection was prepared for the NT because of its unique mortality rate age profile. 


\subsection{Ageing measures}

The numerical ageing measures used in this paper are:

- $\quad$ Population aged 65+

- Population at ages with remaining life expectancy of under 15 years $(R L E<15)$

- Population at ages where age-specific death rates are greater than 0.01 (ASDR>0.01).

The population aged $65+$ is a traditional ageing measure and widely applied. The $\mathrm{RLE}<15$ indicator was selected because of its growing popularity and therefore ability to enable comparisons with other studies using it (Sanderson and Scherbov 2013). The ASDR $>0.01$ measure was selected because it provides an approximate and easily calculable way of defining the older population more likely to experience health problems (Falkingham 2016). Although both 15 years of remaining life expectancy and a death rate of $1 \%$ remain arbitrary measures, they do possess the important feature of being defined by mortality rather than a fixed age. They are also relatively easy to calculate, and do not possess the additional data requirements (such as age-specific labour force participation or disability) of some more complex ageing measures.

Both our selected 'characteristics' ageing measures first require estimation of the exact age where life expectancy is exactly 15 years and the age where the ASDR equals 0.01 . This was calculated separately for males and females and interpolated linearly between single year age intervals in annual period life tables. The male and female populations above those age cut-offs were then aggregated. More refined age cut-offs could have been obtained with cohort life tables, but due to their unavailability and the small difference it would have made, we made use of period life tables.

The equivalent structural ageing measures used in the paper are:

- $\quad$ Percentage of the population aged 65+

- Percentage of the population in age groups with $\mathrm{RLE}<15$

- Percentage of the population in age groups with ASDR $>0.01$

all of which use the numerical ageing measures above as numerators and the total population as denominators.

\section{The extent of population ageing in Australia}

\subsection{National-level trends}

The extent of Australia's past and projected population ageing is illustrated in Figure 1. The upper graph shows the growth of the older population in terms of absolute numbers (numerical ageing), while the lower graph shows the proportion of the total population in the older age group (structural ageing). The traditional ageing measure, based on an older age group cut-off of age 65 , is shown in black. The red lines indicate the older population defined by less than 15 remaining years of life expectancy ( $R L E<15)$, which vary from 63.7 and 60.8 years for females and males respectively in 1921, through to 74.4 and 71.8 years by 2018 , and then 78.9 and 77.8 years by the end of the projection horizon. The blue lines refer to the older population defined by age-specific death rates above 0.01 (ASDR>0.01). In 1921 rates of 0.01 were reached by ages 53.0 and 47.6 years for females and males respectively, by ages 70.8 and 65.5 in 2018, and are projected to rise to ages 79.4 and 78.4 years by the end of the projections. 

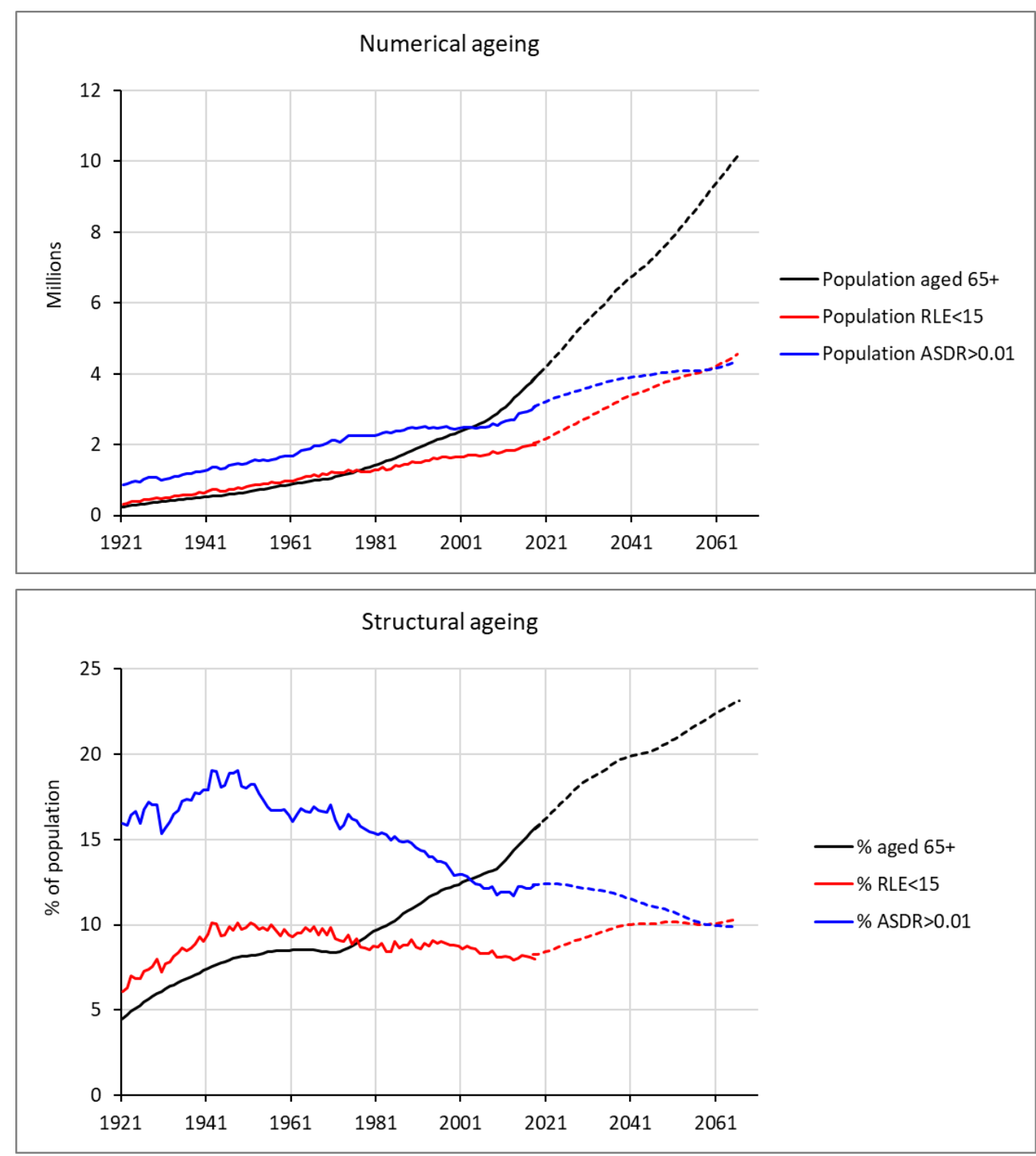

Figure 1: Numerical and structural ageing of Australia's population, 1921-2066

Source: Authors' calculations from ABS data (solid lines) and own projections (dashed lines)

The number of people aged 65+ has grown substantially since 1921 and has been growing particularly fast since around 2011 when the oldest of the baby boom generation started turning age 65 (Figure 1, upper graph). Currently the $65+$ population stands at about 4 million. The projections suggest growth will continue over the coming decades, with the population of this age group reaching just over 10 million by 2066. This is a very substantial increase. However, the two alternative ageing measures paint a less dramatic picture. The population with $R L E<15$ has grown at a roughly steady pace over the long-run, with just a slight uptick in growth observed very recently. Growth of the older population defined as $\mathrm{RLE}<15$ has been notably slower in the past than that of the population aged $65+$. The projections suggest faster numerical ageing in coming decades, with the RLE $<15$ population increasing from about 2 million today to 4.5 million by the end of the projections. The population with $A S D R>0.01$ has also grown at a fairly gradual pace over the longrun, with growth interrupted during the 1990s and 2000s, followed by a return to growth in the most recent decade. The population defined in this way is currently about 3 million. By the end of the projections it is anticipated to have grown to around 4.4 million. 
In terms of structural population ageing (Figure 1, lower graph), the proportion of the population aged $65+$ has increased substantially in recent years and is currently around $16 \%$. It is projected to pass $23 \%$ by the mid-2060s. This rapid structural ageing trajectory indicated by the traditional ageing measure stands in stark contrast to ageing as measured by the proportions of the population with $\mathrm{RLE}<15$ and $\mathrm{ASDR}>0.01$. The proportion of the population with $\mathrm{RLE}<15$ has been slowly declining from about $10 \%$ since the mid-20th century, and is projected to increase modestly over the next two decades to return to about the same level and then remain fairly steady. The proportion of the population with ASDR $>0.01$ has also been mostly declining since the mid-20th century, from around $18 \%$ then to about $12 \%$ today, and is projected to fall further over the coming decades.

\subsection{State and Territory trends}

State and Territory ageing trends are illustrated in Figures 2 and 3. Figure 2 shows numerical ageing while Figure 3 focuses on structural ageing. With respect to numerical ageing, all jurisdictions have experienced substantial growth of their $65+$ populations over the past half century shown in the graphs, with an acceleration of ageing occurring in the last decade. South Australia's 65+ population has grown the least over the most recent decade (increasing by 32\% between 2009 and 2019) while the Northern Territory's numerical ageing has been the most rapid (72\% growth). As the graphs show, all States and Territories are projected to undergo rapid growth of their 65+ populations over the next 50 years.

However, from the perspective of the size of the population with $\mathrm{RLE}<15$, most States and Territories have experienced more modest amounts of numerical ageing over the past half century. For some jurisdictions there are periods of little change in this population in the last decade of the 20th century and first decade of the 21st. Victoria has aged the least according to this measure (with the population of $R L E<15$ increasing by $43 \%$ between 1971 and 2019) while the two territories' populations have aged the most, albeit from a low base. The population with RLE<15 in the ACT has increased by $445 \%$ between 1971 and 2019 while in the Northern Territory the growth was $223 \%$.

Numerical ageing as measured by growth in the population with ASDR $>0.01$ is also relatively modest, and, again for some jurisdictions, includes periods of no growth during the 1990s and 2000s. As Figure 2 shows, projected growth of the ASDR $>0.01$ population is variable between States and Territories. In the future South Australia and Tasmania are expected to experience growth, and then decline, of this population. Projections for the Northern Territory are always highly uncertain, but it appears the ASDR>0.01 population in the Territory will not increase.

Figure 3 presents past and possible future trends in structural ageing amongst the State and Territory populations. It is clear that the percentage of the population aged $65+$ has increased substantially in all jurisdictions over the past half century, with an acceleration of ageing observed over the last decade or so. Increases are projected to continue for all States and Territories for the projection horizon shown in the graphs. By 2066 the proportion of the population aged 65+ is expected to vary from $13 \%$ in the Northern Territory to $31 \%$ in Tasmania. 

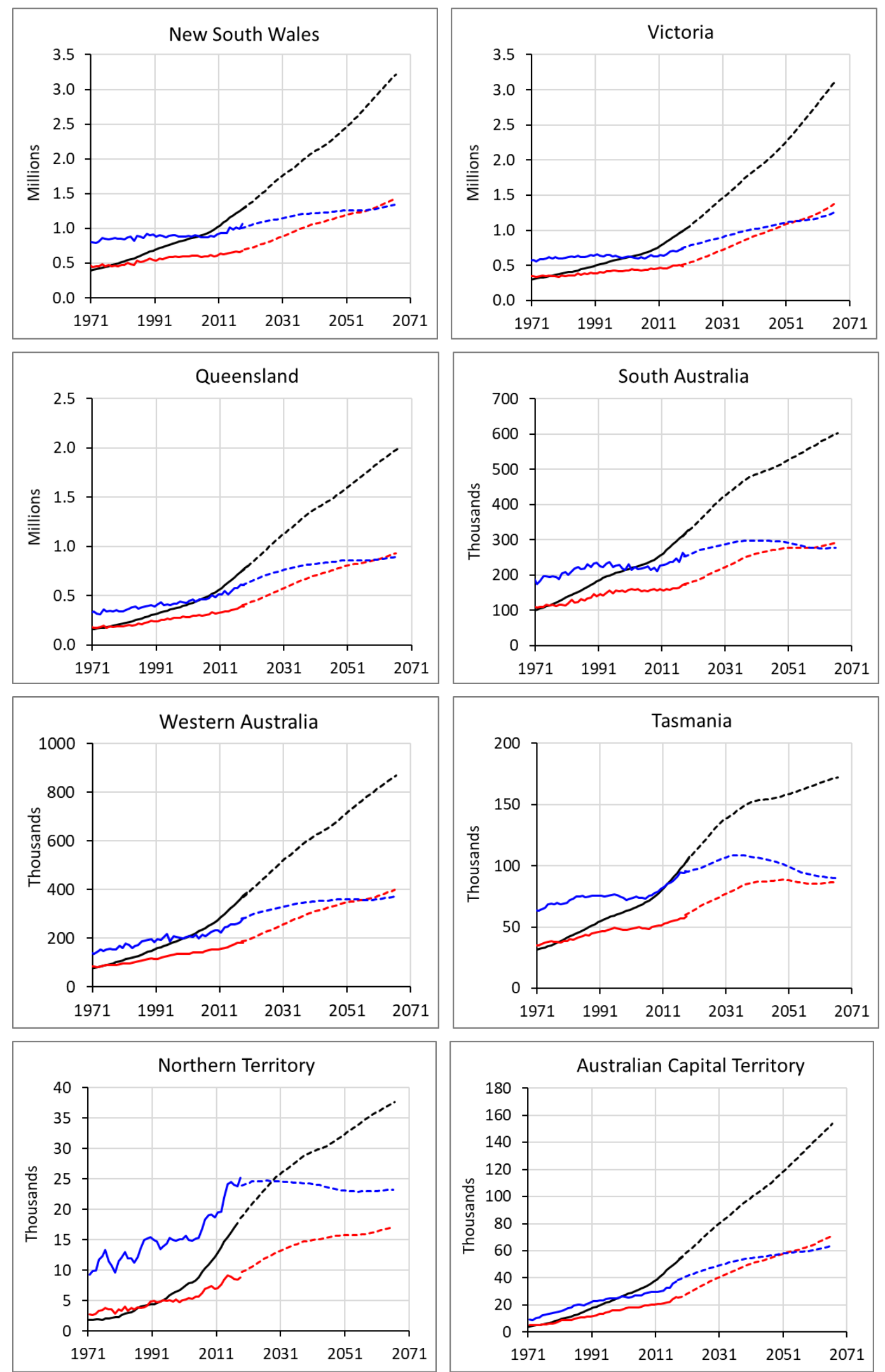

- Population aged $65+$

- Population RLE<15

- Population ASDR $>0.01$

Figure 2: Numerical ageing of State and Territory populations, 1971-2066

Source: Authors' calculations from ABS data (solid lines) and own projections (dashed lines) 

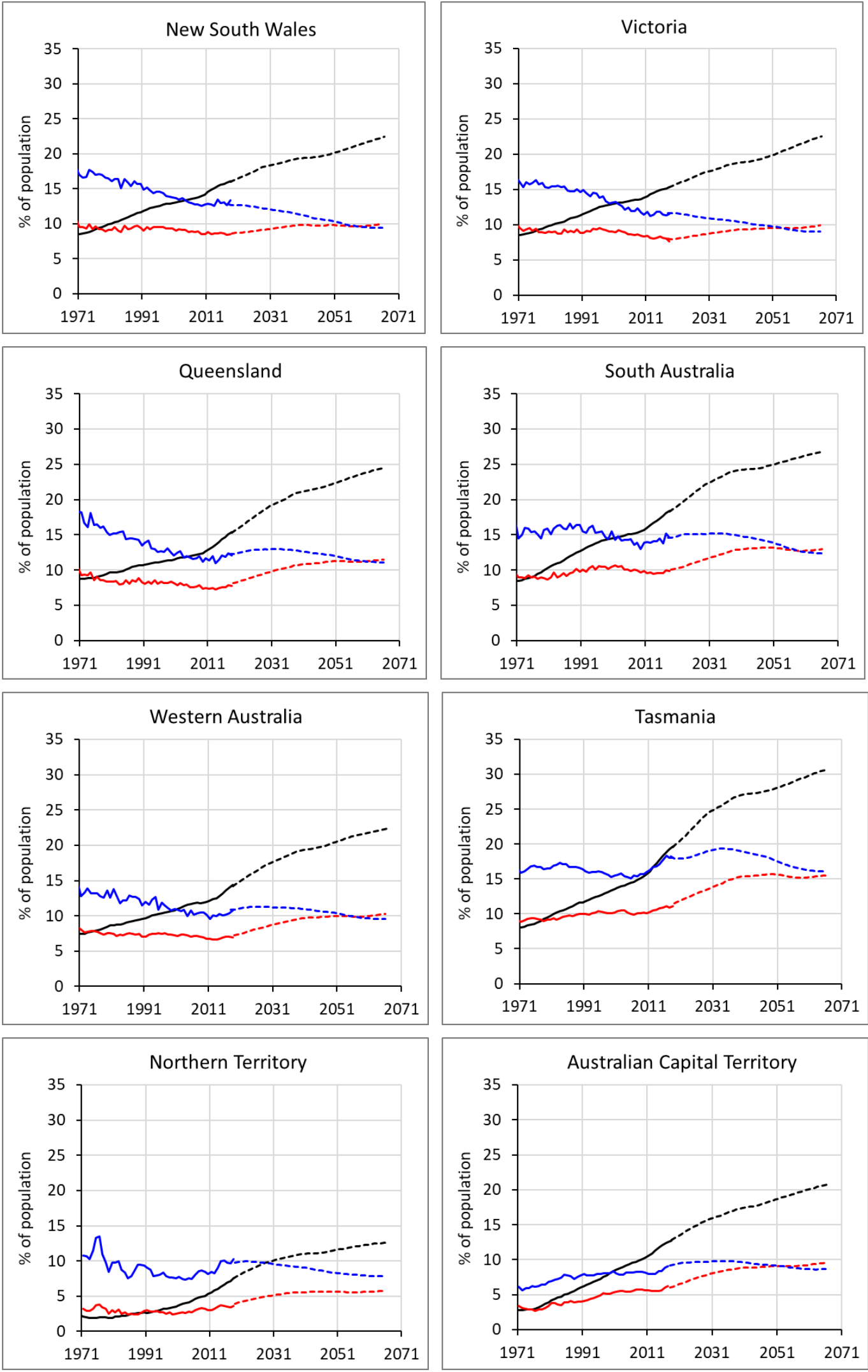

- $\%$ aged $65+\quad-\%$ population $\mathrm{RLE}<15$

— $\%$ population ASDR $>0.01$

Figure 3: Structural ageing of State and Territory populations, 1971-2066

Source: Authors' calculations from ABS data (solid lines) and own projections (dashed lines) 
But while the share of the population aged 65 and over will rise considerably in all jurisdictions, the share of the older population as defined by the mortality measures $R L E<15$ and ASDR $>0.01$ is unlikely to rise in many cases (Figure 3). The percentage of the population with $R L E<15$ is projected to increase in all jurisdictions initially before decelerating and then remaining roughly steady. The share of the population with ASDR $>0.01$ is projected to decline gradually, or increase slightly before declining, across all States and Territories.

\subsection{Understanding the alternative ageing trends}

As shown above, population ageing can be measured in a variety of ways. If ageing is measured in the traditional way using an age cut-off of 65 it gives very different results from ageing measured with a variable cut-off age dependent on a selected mortality characteristic. Why does ageing measured by the traditional and alternative ageing measures differ so much?

In short, they measure different aspects of population ageing. Projected growth in the numbers of people aged 65+ can be attributed to increasing sizes of birth cohorts over time, net overseas plus interstate migration gains and improved survival (Preston and Stokes 2012). Understanding growth in older populations defined by a mortality characteristic, such as the population with $R L E<15$ or ASDR $>0.01$, is slightly less straightforward. The growth of the older population defined in this way depends on the interaction between the growth of age-sex population groups above age 65 and the rate of progress in mortality which determines the older age group starting age.

Take the example of the population with $R L E<15$. Australia's population in the $65+$ age group is projected to grow substantially over the coming decades. At the same time, declining death rates mean that the starting age of the $R L E<15$ group rises, increasing from about 74 years for females and 71 years for males in 2016 to about 79 and 78 years, respectively, by the end of the projection horizon. Figure 4 illustrates the population aged 65+ in 2016, 2041 and 2066 divided into the older population with less than 15 years of life expectancy remaining ( $R L E<15$; shown in pink) and the younger population with more than 15 years remaining ( $R L E>15$; shown in grey). With the older population defined as $R L E<15$, there is still substantial projected numerical ageing because the growth of population at higher ages is greater than the population excluded at lower ages due to the upward shift in the starting age of this group. As a proportion of the 65+ population, however, the $\mathrm{RLE}<15$ group is projected to occupy a declining share. The increasing share of the $65+$ population with more than 15 years life expectancy remaining reflects projected progress in reducing mortality at older ages.

Explaining the trends in structural ageing requires attention be paid to overall population size, which forms the denominator of the proportions of the population in the $R L E<15$ and ASDR $>0.01$ age groups. As shown in Figures 1 and 3, structural ageing according to the RLE $<15$ and ASDR $>0.01$ populations is projected to be modest or non-existent in the future. In Australia as a whole, and many of the States and Territories, overall population growth is projected to be strong. This is due to the combination of net overseas migration gains, mid-range fertility, and population momentum. It means that, although the size of populations with $R L E<15$ and ASDR $>0.01$ are projected to grow, they will not always increase as a share of total population. 

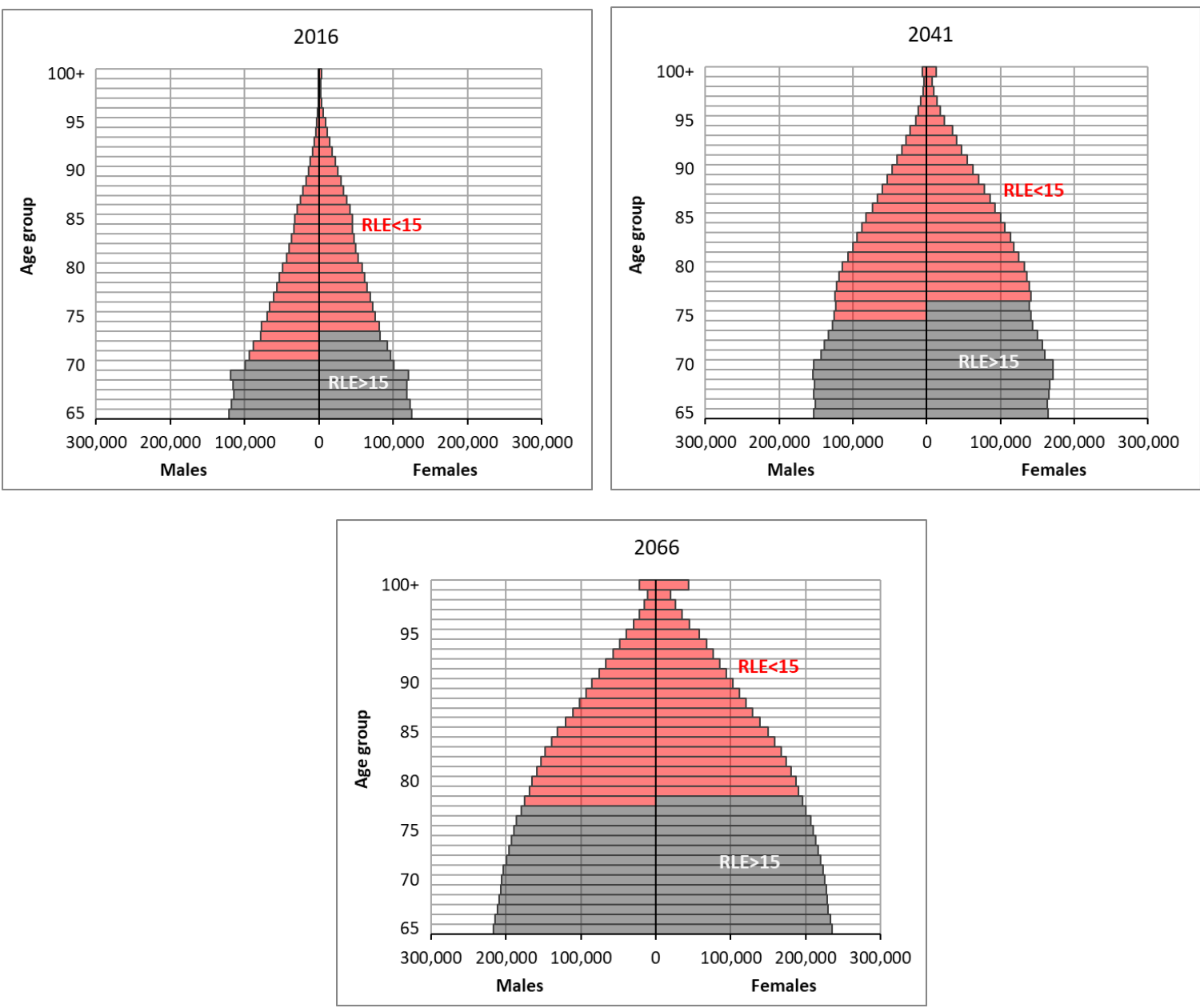

Figure 4: The age-sex structure of Australia's population aged 65+ in 2016, 2041 and 2066, divided into those with remaining life expectancy under 15 years (RLE<15) and those with more than 15 years remaining (RLE>15)

Source: Authors' projections

Note: The cut-off ages for RLE<15 had to be rounded to the nearest integer in these graphs

\section{Conclusion}

This paper has presented past and projected future trends in population ageing in Australia. From the perspective of traditional ageing measures, Australia's population is currently undergoing both numerical and structural population ageing and will continue to do so for the entire projection horizon reported here (to 2066). Ageing measured from a characteristics approach using the mortality definitions of RLE $<15$ and ASDR $>0.01$ presents a complementary perspective. The RLE $<15$ population has grown steadily over the past half century and is projected to grow more strongly into the future nationally, with some variation by State and Territory. The population with ASDR $>0.01$ has grown modestly over the past half century, though with some interruptions, and at the national scale is projected to grow for much of the next half century. Amongst the States and territories future growth of the ASDR $>0.01$ population growth is more varied. Structural population ageing according to the two alternative ageing measures has not occurred since the mid-20th century. At the national scale some ageing is projected to occur in the future according to the $R L E<15$ measure but not according to the ASDR>0.01 measure. The projections therefore present good news: the population 
above age 65 will grow but populations in the higher mortality groups of $R L E<15$ and ASDR $>0.01$ are not expected to grow as fast.

We argue that this combination of ageing measures (traditional and mortality-based) provides demographers with a more detailed understanding of population ageing. In particular, the use of mortality-based measures may help when examining levels of structural and numerical ageing in different sub-groups of national populations. One example is the ageing of non-Indigenous and Aboriginal and Torres Strait Islander populations. Within the gerontological and public health literature, there is considerable debate about what constitutes 'old age' for Australia's First Nations peoples. A general consensus, however, has formed that using a younger age cut-off of 45 or 50 is more appropriate for gerontological studies due to (i) a considerable gap in life expectancy between Aboriginal and non-Indigenous Australians (ABS 2013; AIHW 2017), (ii) many conditions and comorbidities as well as frailties commonly associated with ageing occurring at earlier ages in this population (AlHW 2016; Gubhaju et al. 2013; Hyde et al. 2016), and (iii) government programs such as those governing access to specific aged care services being available to Aboriginal and Torres Strait Islanders from earlier ages compared to non-Indigenous Australians.

Despite the potential benefits of the measures we outline, projections are uncertain, and this is one of the limitations of the paper. As a general rule, projections are more uncertain the further into the future they extend, the smaller the population being projected, and the greater the amount of migration populations experience. Past projections for Northern Territory have been shown to be especially prone to error (Wilson 2012). And demographic conditions may well change; different migration policy scenarios can make substantial differences to projected structural ageing (e.g. McDonald 2016). Major external shocks can also affect demographic change. Because these projections were prepared before the emergence of COVID-19, the demographic impacts of the pandemic have not been incorporated in our projection assumptions. The lower net overseas migration which Australia is likely to experience for a while will affect structural population ageing, but the size of this impact will depend heavily upon Government policy regarding the Migration Program over the medium term. Given the young age structure of net overseas migration, COVID-19 shocks will have a negligible impact on numerical ageing. Finally, a test run of our projection model over the period 2011 to 2016 revealed the $65+$ numerical and structural ageing measures to be projected very accurately after 5 years, with slightly less accuracy achieved for $\mathrm{RLE}<15$ measures, and slightly less accuracy still for ASDR>0.01 measures.

In summary, this paper demonstrates that the extent of past and future population ageing in Australia, and in the States and Territories, depends on how it is viewed. Just two alterative ageing measures were considered, though many other characteristics-based measures could have been chosen. The main conclusion for researchers and policy makers is that population ageing can be viewed from a variety of perspectives, and that the most appropriate measure depends on the purpose of the study. It is important that the extent and speed of population ageing not be misinterpreted as a result of relying solely on one ageing measure. If the focus is on the retired population, then measures based on the economically inactive population at the older ages are recommended; if the study is about residential aged care needs, then the population requiring this care should be the population of interest in any ageing measure; if the focus is on health costs, then an ageing measure focusing on age-specific health costs is most appropriate. For general 
demographic analysis the use of a traditional measure (using age 65 as the cut-off age) in combination with a mortality-based measure, such as one founded on $R L E<15$, is helpful.

\section{Key messages}

- Australia has been experiencing numerical population ageing for a long time according to both traditional and alternative characteristics-based ageing measures. There will be many more people in the older population (however defined) in coming decades.

- Structural population ageing according to the traditional measure of the percentage of the population aged $65+$ has been occurring since the 1970 s and is projected to continue in the decades ahead.

- The proportion of Australia's population with less than 15 years remaining life expectancy ( $R L E<15)$, and the proportion of the population with age-specific death rates above 0.01 (ASDR $>0.01$ ), have generally declined over recent decades. Structural population ageing is projected for the next two decades according to $R L E<15$, but not according to ASDR $>0.01$.

- Population ageing can be viewed from a variety of perspectives, and the most appropriate ageing measure depends on the purpose of the study. For general demographic analysis a combination of both traditional and mortality-based ageing measures is recommended.

\section{Acknowledgements}

This research was supported by the Australian Research Council Centre of Excellence in Population Ageing Research (project number CE170100005). We are grateful to the anonymous reviewers for their helpful comments on the original version of the paper.

\section{Data availability}

The population projections, including age cut-offs for the RLE $<15$ and ASDR $>0.01$ measures, are available in an Excel workbook at https://figshare.com/articles/Population ageing projections for Australia/12228008.

\section{References}

ABS (2013) Life Tables for Aboriginal and Torres Strait Islander Australians, 2010-2012. Catalogue No. 3302.0.55.003. Canberra: ABS.

ABS (2019a) Australian Demographic Statistics, Jun 2019. Catalogue No. 3101.0. Canberra: ABS.

ABS (2019b) Deaths, Australia, 2018. Catalogue No. 3302.0. Canberra: ABS.

Australian Institute of Health and Welfare (AIHW) (2016) Australian Burden of Disease Study: Impact and causes of illness and death in Aboriginal and Torres Strait Islander People. Australian Burden of Disease Study series no.6. Catalogue No. BOD7. Canberra: Australian Institute of Health and Welfare.

Australian Institute of Health and Welfare (AIHW) (2017) Trends in Indigenous mortality and life expectancy, 2001-2015: evidence from the Enhanced Mortality Database. Catalogue No. IHW 174. Canberra: Australian Institute of Health and Welfare.

Chomik R, McDonald P and Piggott J (2016) Population ageing in Asia and the Pacific: Dependency metrics for policy. The Journal of the Economics of Ageing 8: 5-18. 
Ediev D M (2008) Extrapolative projections of mortality: towards a more consistent method. Part I: The Central Scenario. Working Paper 3/2008. Vienna Institute for Demography, Austria.

Falkingham J (2016) The changing meaning of old age. ESRC Centre for Population Change Briefing 31. University of Southampton, UK. Available at: http://www.cpc.ac.uk/docs/BP31 The changing meaning of old age.pdf

Gubhaju L, McNamara J, Banks E, Joshy G, Raphael B, Williamson A and Eades S (2013) The overall health and risk factor profile of Australian Aboriginal and Torres Strait Islander participants from the 45 and up study. BMC Public Health 13: 661.

HMD (2019) Human Mortality Database. University of California, Berkeley (USA), and Max Planck Institute for Demographic Research (Germany). Available at: www.mortality.org.

Hobbs F (2004) Age and sex composition. In Siegel J S and Swanson D A (eds) The Methods and Materials of Demography. Second edition. Amsterdam: Elsevier; pp 125-173.

Hyde Z, Flicker L, Smith K, Atkinson D, Fenner S, Skeat L and Lo Giudice D (2016) Prevalence and incidence of frailty in Aboriginal Australians, and association with mortality and disability. Maturitas 87: 8994.

Jackson N and Felmingham B (2002) As the population clock winds down: indicative effects of population ageing in Australia's states and territories. Journal of Population Research 19(2): 97-117.

Kendig H, McDonald P and Piggott J (eds) Population Ageing and Australia's Future. Canberra: ANU Press.

Lutz W, Sanderson W and Scherbov S (2008) The coming acceleration of global population ageing. Nature 451: 716-719.

McDonald P (2016) Ageing in Australia: population changes and responses. In Kendig H, McDonald P and Piggott J (eds) Population Ageing and Australia's Future. Canberra: ANU Press; pp 65-83.

Preston S H, Heuveline P and Guillot M (2001) Demography: Measuring and Modeling Population Processes. Oxford: Blackwell.

Preston S H and Stokes A (2012) Sources of population aging in more and less developed countries. Population and Development Review 38(2): 221-236.

Rowland D (2003) Demographic Methods and Concepts. Oxford: Oxford University Press.

Sanderson W C and Scherbov S (2007) A new perspective on population aging. Demographic Research 16(2): 27-58.

Sanderson W C and Scherbov S (2015) Are we overly dependent on conventional dependency ratios? Population and Development Review 41(4): 687-708.

Skirbekk V, Loichinger E and Weber D (2012) Variation in cognitive functioning as a refined approach to comparing aging across countries. Proceedings of the National Academy of Sciences 109(3): 770774.

Spijker J (2015) Alternative indicators of population ageing: an inventory. Working Papers 4/2015. Vienna Institute of Demography, Austria.

Spijker J and Maclnnes J (2013) Population ageing: the timebomb that isn't? British Medical Journal 347: f6598.

UN (2019) World Population Ageing 2019. New York: UN.

Wilson T (2012) Forecast accuracy and uncertainty of Australian Bureau of Statistics state and territory population projections. International Journal of Population Research. Volume 2012

Wilson T (2018) Evaluation of simple methods for regional mortality forecasts. Genus 74:14.

Wilson T and Temple J (2020) The rapid growth of Australia's advanced age population. Unpublished paper. 